\title{
Successful Treatment of Palpebral Pyogenic Granuloma with Topical Timolol: A Case Report
}

\section{El Kaissoumi Loubna ${ }^{1 *}$, El Moize Zakaria ${ }^{1}$ and Cherkaoui Ouafae ${ }^{2}$}

${ }^{1}$ Resident in Ophthalmology A Department, Hôpital des Spécialités, University Mohammed V, Rabat, Morocco

${ }^{2}$ Head of Ophthalmology A Department, Hôpital des Spécialités, University

Mohammed V, Rabat, Morocco

*Corresponding Author: El Kaissoumi Loubna, Resident in Ophthalmology

A Department, Hôpital des Spécialités, University Mohammed V, Rabat, Morocco.
Received: March 05, 2021

Published: March 18, 2021

(C) All rights are reserved by El Kaissoumi

Loubna., et al.

\section{Abstract}

Pyogenic granuloma is a benign vascular tumor appearing usually as a response of a local tissue to an irritation or a trauma.

This lesion can be sessile or pedunculated, and it can measure few millimeters or several centimeters. It is usually located on the face or the fingers.

It generally occurs among young patients and it's seems to have a female predilection prevalence.

It can be induced by trauma, drugs, or may appear spontaneously, like it was the case of our patient.

Different therapeutic options may be proposed to treat pyogenic granulomas, some being more invasive like curettage, shave removal, surgical excision by electrocautery, laser, microembolization or sclerotherapy.

Topical timolol can be an interesting option to treat pyogenic granulomas, but further studies have to be done to demonstrate its effectiveness in the treatment of this pathological entity.

Keywords: Palpebral Lesion; Pyogenic Granuloma; Topical Timolol

\section{Background}

Pyogenic granuloma is a benign vascular tumor appearing usually as the response of a local tissue to an irritation or a trauma.

This lesion can be sessile or pedunculated, and it can measure few millimeters or several centimeters.

It is usually located on the face or the fingers, but pyogenic granuloma can be located anywhere else.

It generally occurs among young patients and its seems to have a female predilection prevalence.

Pyogenic granuloma is misnamed 'pyogenic' since there is no pus. In fact, it is histologically a granuloma and its main compo- nents are collagen and vessels, that decrease with the growth of the granuloma and gives it the characteristically clinical pink reddish color.

\section{Case Report}

A 38-year-old woman with no medical history presented to the ophthalmology emergency room with a firm pedunculated lesion on her right upper eyelid. The lesion had been progressively increasing in size for over a period of 10 days. Three days before she presented, she noticed a minimal bleeding from the lesion, leading her to present to the emergency room.

The patient didn't report any history of eyelid trauma, nor ocular surgery. She didn't take any medication previously and had no medical history. 
The clinical course and physical examination suggested the diagnostic of a pyogenic granuloma on the upper right eyelid (Figure 1 and 2) as the lesion was firm, pedunculated, reddish.

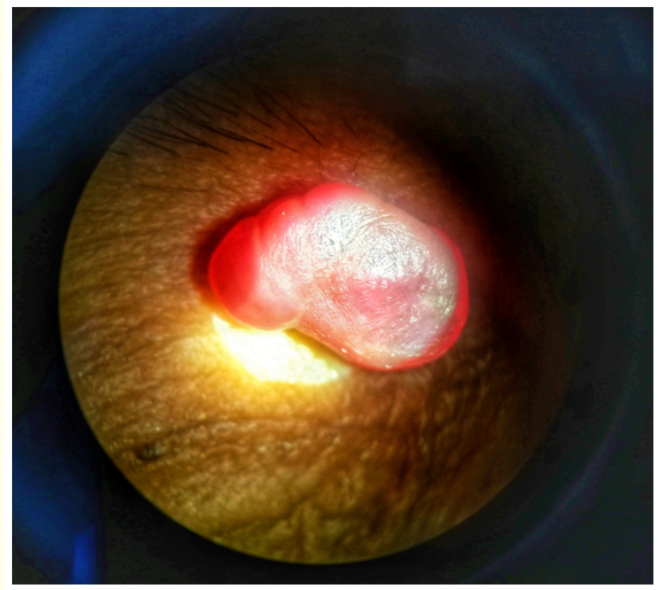

Figure 1: Biomicroscopic aspect (close view) of the palpebral pyogenic granuloma before treatment.

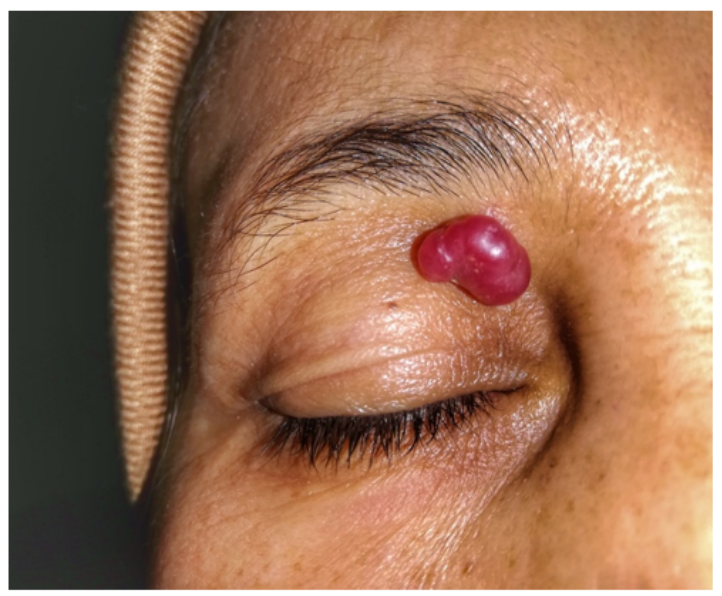

Figure 2: Pyogenic granuloma on the upper eyelid in a 38 year-old patient before treatment.

After discussing the different therapeutic options with the patient, we opted for a non-invasive therapy using topical timolol $0,5 \%$, applied twice daily, for likely 11 weeks.
We noticed an involution of the granuloma (Figure 3) and the final cosmetic outcome satisfied our patient (Figure 4), who didn't report any side effects of the treatment.

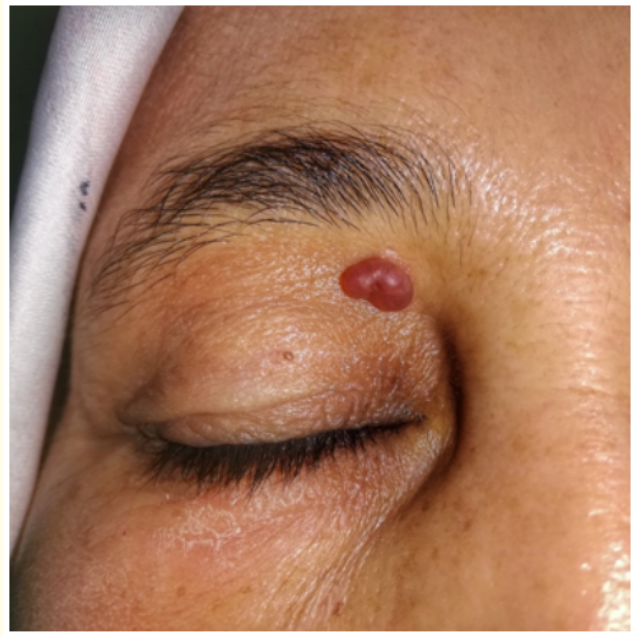

Figure 3: Aspect of the pyogenic granuloma after 6 weeks of treatment with topical timolol.

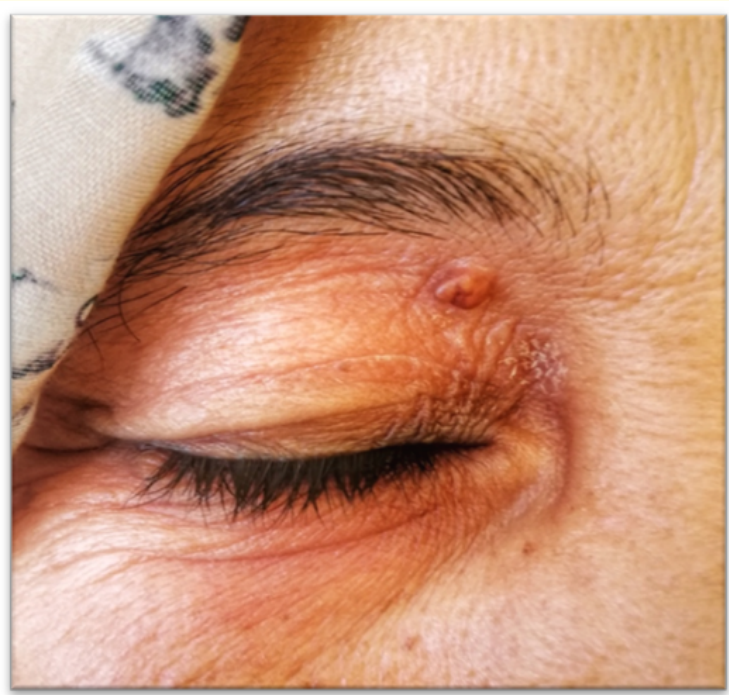

Figure 4: Aspect of the pyogenic granuloma after 11 weeks of treatment with topical timolol. 
The patient was seen 3 months after the end of the treatment with no signs of recurrence.

\section{Discussion}

Pyogenic granuloma is a benign vascular tumor with a quick potential of growth [1], that can be localized on the skin or the mucosae, mostly encountered on the face and fingers [2].

There might be a slight predominance in women, and happens more frequently among young population [3].

It can be induced by trauma, drugs, or may appear spontaneously, like it was the case of our patient.

Different therapeutic options may be proposed to treat pyogenic granulomas, some being more invasive like curettage, shave removal, surgical excision by electrocautery, laser [4], microembolization or sclerotherapy.

Some studies and recent case reports were found after a literature review, supporting the effectiveness of topical timolol in the treatment of conjunctival pyogenic granulomas [5], suggesting it as an interesting non-invasive treatment in pyogenic granuloma, but larger studies are still necessary to confirm it [6].

\section{Conclusion}

Pyogenic granuloma is a benign vascular tumor appearing usually as the response of a local tissue to an irritation or a trauma.

Different therapeutic options may be proposed to treat it, and topical timolol might be an interesting and non-invasive that needs to be more explored with larger studies including more patients.

\section{Disclosure}

There are no financial conflicts of interest to disclose.

\section{Bibliography}

1. Mills SE., et al. "Lobular capillary hemangioma: the underlying lesion of pyogenic granuloma. A study of 73 cases from the oral and nasal mucous membranes". The American Journal of Surgical Pathology 4 (1980): 470-479.

2. Fortna RR and Junkins-Hopkins JM. "A case of lobular capillary hemangioma (pyogenic granuloma), localized to the subcutaneous tissue and a review of the literature". The American Journal of Dermatopathology 29 (2007): 408-411.
3. Nthumba PM. "Giant pyogenic granuloma of the thigh: a case report". Journal of Medical Case Reports 2 (2008): 95.

4. Rai S., et al. "Laser: a powerful tool for treatment of pyogenic granuloma". Journal of Cutaneous and Aesthetic Surgery 4 (2011): 144-147.

5. Nair AG., et al. "Topical timolol for the treatment of conjunctival pyogenic granulomas: Outcomes and effect on intraocular pressure". Indian Journal of Ophthalmology 68.10 (2020): 2170-2174.

6. Chiriac A., et al. "Noninvasive Treatment of Pyogenic Granulomas in Young Children with Topical Timolol and Trichloroacetic Acid". The Journal of Pediatrics 169 (2016): 322-322.

\section{Assets from publication with us}

- Prompt Acknowledgement after receiving the article

- Thorough Double blinded peer review

- Rapid Publication

- Issue of Publication Certificate

- High visibility of your Published work

Website: www.actascientific.com/

Submit Article: www.actascientific.com/submission.php Email us: editor@actascientific.com

Contact us: +919182824667 